\title{
Factors Associated with the Quality of Life in the Elderly with Non-Communicable Diseases in Nakhon Si Thammarat, Thailand
}

\author{
Nadanong Jengan ${ }^{1}$, Anunya Pradidthaprech ${ }^{2}$, Piyapong Choomsri ${ }^{3}$, \\ Karnjana Sae-Ung ${ }^{4}$, Panee Sitakalin ${ }^{2}$ and Pokkamol Laoraksawong, ${ }^{2, *}$ \\ ${ }^{I}$ Bangsala sub-district Health Promoting Hospital, Nakhon Si Thammarat 80140, Thailand \\ ${ }^{2}$ School of Health Science, Sukhothai Thammathirat Open University, Nonthaburi 11120, Thailand \\ ${ }^{3}$ Program of Public Health, Faculty of Science and Technology, Loei Rajabhat University, \\ Loei 42000, Thailand \\ ${ }^{4}$ Program of Occupational Health and Safety, Faculty of Liberal Arts and Science, \\ Sisaket Rajabhat University, Sisaket 33000, Thailand
}

('Corresponding author's e-mail: pokkamol.3108@gmail.com)

Received: 8 April 2021, Revised: 10 June 2021, Accepted: 20 June 2021

\begin{abstract}
Medical technology has rapidly developed which increases life expectancy and multiplies the number of an aging population. This trend can be found in many countries, including Thailand. When people live longer, behavior-related illnesses like noncommunicable diseases (NCDs) will be ubiquitous. This point will introduce another burden on global health. NCDs are a cause of death and carry a high cost for extending health in the long-term and decrease the quality of life (QOL) for the elderly. This study was aimed to examine the factors associated with the QOL of the elderly who are having NCDs in Thailand. The sample size was 157 elderly persons aged $\geq 60$ years old who lived in Nakhon Si Thammarat, Thailand. The subjects were randomized by the sampling technique. The data were collected using the WHO-QOLBREF questionnaire from 15 May to 10 December 2019. The data were analyzed by descriptive statistics and multiple logistic regression analysis. The total of 157 elderlies with a mean $( \pm \mathrm{SD})$ age of $73.76( \pm 8.24)$ years old. The QOL in the elderly with NCDs was qualified at a fair level $(63.06 \%)$. The significant factors associating with QOL in the elderly with NCDs were income sufficiency (Odd ratio $[\mathrm{OR}]=2.8,95 \% \mathrm{CI}: 1.04$ to 7.52 ), self-esteem $(\mathrm{OR}=9.75,95 \% \mathrm{CI}: 2.74$ to 34.70$)$, and social support $(\mathrm{OR}=0.12,95 \% \mathrm{CI}$ : 0.03 to 0.43$)$. These results demonstrated that we should be aware of promoting self-esteem, getting social support, and maintaining sufficient income for the elderly. Therefore, it is recommended that the elderly should be encouraged to adapt and plan appropriate behavior and lifestyle in order to improve their quality of life.
\end{abstract}

Keywords: Quality of life, The elderly, Non-communicable diseases, Thailand

\section{Introduction}

Currently, it has been known that the number of aging population is dramatically increasing, especially in developing countries, in which the World Health Organization (WHO) anticipated that the number of aging population will be increased to 1.5 billion in 2050 [1]. The increasing of aging population was caused by the improvement of health service systems over the past century $[1,2]$. The death from infectious diseases is more curable, however, NCDs (including diabetes, hypertension, and cardiovascular, etc.) tend to affect more and more in the aging population, which can pose a threat to global health $[1,3]$. These NCDs are likely to be a cause of death and carry a high cost for extending the health in the long-term. The diseases may also decrease self-esteem, undermine workforce productivity as well as the QOL for the elderly [1,4,5]. Moreover, socioeconomics and environmental factors can affect happiness and QOL in the elderly [6].

Thailand, known as a lower middle-income country, is becoming an aging society [2]. The proportion of elders ( $\geq 60$ years) in Thailand is approximately $14.90 \%$ of the total population [7-9]. These people may be suffering from debilitating diseases and functional disabilities, which can lead to an increase in the elderly dependence ratio. Among elders in Thailand, the number of deaths caused by NCDs is much higher than caused by communicable diseases [10]. NCDs' death accounts for $76.0 \%$ of 
all deaths in old people. Diabetes and heart disease are the most reported NCDs for hospitalizations in the country [10].

The elderly rate and the aging index in southern Thailand are 13.2 and $61.2 \%$, respectively. Nakhon Si Thammarat province had the highest elderly rate and the aging index, which were 2.8 and $84.0 \%$, respectively [8]. In 2018, this province had a NCDs prevalence of $5.02 \%$ which was a high number of health problems in the elderly [11]. Moreover, these diseases predispose aging people to suffer from the high costs of treatment, disability, mental health, and limited physical activity. This study was aimed to examine the QOL and analyzed the essential factors that can be associated with the QOL in the elderly with NCDs in a rural area of southern Thailand. The result could be used as fundamental information to build a viable long-term health care system regarding the QOL in the elderly with NCDs.

\section{Materials and methods}

\section{Study design}

A cross-sectional survey was carried out from 15 May to 10 December 2019 in the Bangsala subdistrict, Pak Phanang district, Nakhon Si Thammarat, Thailand. The main land use is for rubber plantations and farming. This sub-district has aging population of approximately $27.47 \%$ and the elderly dependency ratio was 52.09 [12]. The participants were randomly selected from patients with diagnosed diabetes mellitus and hypertension as confirmed by internal medicine doctors. The inclusion criteria were fasting plasma glucose values of $\geq 7.0 \mathrm{mmol} / \mathrm{L}(126 \mathrm{mg} / \mathrm{dL})$ and $\mathrm{HbAlc} \geq 6.5 \%$ (48 $\mathrm{mmol} / \mathrm{mol})$ for diabetes mellitus [13], and blood pressure $\geq 140$ - 159 or $\geq 90-99 \mathrm{mmHg}$ for hypertension [14]. Moreover, the participants were elderly who aged $\geq 60$ years old, lived in areas. The participants who refused to give a consent were excluded in this study. So, the included population in this study was 223 .

\section{Study population, sample size, and sampling technique}

The population of this study was elderly aged $\geq 60$ years old with a history of NCDs. The sample size was calculated by the finite population proportion method [15]. It was calculated using a prevalence rate (p) of $52.0 \%$, as detailed in a previous study [12], with a $95 \%$ confidence interval $(\mathrm{z}=1.96)$ and a 5 $\%$ margin of error $(d=0.05)$. The calculated sample size was 142 people. However, the authors assumed that the final sample size would end up being reduced by $10 \%$ due to subjects being unable to answer a questionnaire. Thus, we aimed at a sample size of 157 people. The sample size was randomized by the simple sampling technique.

\section{Instruments and data collection}

This study was approved by human ethics from Sukhothai Thammathirat Open University Committee for Human Research (IBB SHS 2018/10004/57). All research was performed in accordance with the Declaration of Helsinki. The objective of the study was fully explained to the participants, and participation was voluntary. Written informed consent was obtained from all participants before data and sample collection. After receiving informed consent from the participants, we interviewed 157 participants by questionnaires. The questionnaire included baseline characteristics, self-esteem, health service system accession, family relationships, social support, and WHOQOL-BREF [16]. This tool had a high level of reliability with Cronbach's alpha of 0.93 . Baseline characteristics included gender, age, education level, occupations, marital status, income, underlying diseases, and health insurance. The selfesteem part consisted of 18 questions such as physical and personal self, which developed from the selfconcept [17]. The health service system part included 16 questions such as health service system accession and service systems' suitability, which developed from the concept of health care access [18]. The family relationships consisted of 12 questions such as social support, information accession, and government or social welfare. Moreover, the social support part consisted of 12 questions. The selfesteem, health service system accession, family relationships, and social support were classified into 3 groups of poor, fair, and best level. The range of scores was between 1 and 5, which means $1-2.33$ were poor, 2.34 - 3.66 were fair, and 3.67 - 5 were best. Furthermore, the WHOQOL-BREF consisted of 26 questions, 24 of which are divided into 4 domains: Physical health, mental health, social relationships, and environment. After the interview, the standard scores in overall QOL were collected in a range from 26 - 130, which 26 - 60 scores refer to poor QOL, 61 - 95 scores refer to fair QOL, and 96 - 130 scores refer to best QOL [16]. Each domain of QOL was categorized into 3 groups of poor, fair, and best level. The range of physical health score was between 7 and 35, meaning that $7-16$ were poor, 17 - 26 were fair, and 27 - 35 were best. The range of mental health domain score was between 6 and 30, which was categorized in 6 - 14 refer to poor, 15 - 22 refer to fair, and 23 - 30 refer to best. The range of social 
relationships domain score was between 3 and 15, which was categorized in 3 groups of poor, fair, and best level of social relationships (3-7, 8-11, and 12 - 15 scores, respectively). Finally, the range of environment domain score was between 8 and 40, which was categorized into 3 groups of poor, fair, and best level of social relationships (8 - 18, 19 - 29, and 30 - 40 scores, respectively) [16].

\section{Statistical analysis}

The frequency, percentage, mean, and standard deviation (SD) are described as the demographic characteristics of the participants. Baseline characteristics, self-esteem, health service system, family relationships, and social support are described by frequency, percentage, minimum, and maximum. The overall QOL, age, and income are described by mean and SD. We classified QOL into 2 groups including poor QOL and best QOL for univariate analysis and multiple logistic regression analysis. Multiple logistic regression analysis was used to investigate the factors associated with QOL in the elderly with NCDs. For adjusting possible confounders, all variables with a $p$-value of less than 0.2 in the univariate analysis were selected according to backward stepwise regression analysis. A $p$-value of less than 0.05 was considered statistically significant. The statistical analysis was conducted using the Statistic Package for Social Sciences (SPSS package) version 17.0 Armonk, New York: IBM.

\section{Results and discussion}

A total of 157 elderlies with a mean $( \pm \mathrm{SD})$ age of $73.76( \pm 8.24)$ years old, were included in this study. The youngest of the elderly was 60 , and the oldest was 95 years old. Most of the participants were 70 - 79 years old $61(38.85 \%)$. One hundred and seven $(68.15 \%)$ of the 157 participants were female, and $50(31.85 \%)$ were male. Ninety-six participants $(61.15 \%)$ lived with a partner. For the educational standpoint, the majority attended only primary school or had no formal education $143(91.08 \%)$, while the rest $(8.92 \%)$ graduated in secondary school or higher. Additionally, $103(65.61 \%)$ participants were unemployed, and 54 (34.39\%) participants were employed. The average income $( \pm \mathrm{SD})$ was $111.64 \$$ $( \pm 103.88 \$)$ with the minimum at $25.68 \$$ and the maximum at $642.05 \$$. Interestingly, around 113 participants $(71.97 \%)$ had an income lower than $160.51 \$$ per month (50th percentile) (according to the USD-THB exchange rate as of 7 May 2020). Most of the participants $113(71.97 \%)$ had an income sufficiency and $133(84.71 \%)$ used universal coverage in health insurance. Moreover, the major underlining disease in elderlies was hypertension (HT) 66 (42.04\%), followed by HT combined with cardiovascular 36 (22.93\%) and HT combined with Diabetes Mellitus (DM) 28 (17.83\%) (Table 1).

The elderly with NCDs had an overall score level of family relationships $4.24( \pm 0.39)$ which was the highest among other factors such as self-esteem, health service system, and social support factors. The results showed that the overall score levels of the health service system were $3.94( \pm 0.44)$, followed by the overall score levels of self-esteem as well as social support which were $3.86( \pm 0.46)$ and 3.73 $( \pm 0.45)$, respectively. So that, most of the participants were at the best level in these factors (Table 2).

Table 1 Baseline characteristic and socio-demographic data of elderly.

\begin{tabular}{ll}
\hline Baseline characteristic & N (\%) $(\mathbf{n}=\mathbf{1 5 7})$ \\
\hline Gender & $50(31.85)$ \\
$\quad$ Male & $107(68.15)$ \\
$\quad$ Female & \\
Age (years) & $50(31.85)$ \\
$\quad 60-69$ & $61(38.85)$ \\
$70-79$ & $46(29.30)$ \\
$\geq 80$ &
\end{tabular}

\section{Living status}

Living without partner

Living with partner 


\begin{tabular}{ll}
\hline Baseline characteristic & $\mathbf{N}(\mathbf{\%}) \mathbf{( n = 1 5 7 )}$ \\
\hline$\quad$ Education levels & $143(91.08)$ \\
$\quad$ Primary school or no formal education & $14(8.92)$ \\
$\quad$ Secondary school or higher & \\
Occupations & $103(65.61)$ \\
$\quad$ Unemployed & $54(34.39)$ \\
$\quad$ Employed (agriculture 48, merchant 6) & \\
Income per month (\$) & $133(84.71)$ \\
$<160.51 \$$ & $24(15.29)$ \\
$\geq 160.51 \$$ & \\
Mean (SD)=111.64 (103.88), Min =25.68, Max $=642.05$ & \\
Income sufficiency & $113(71.97)$ \\
Sufficient income & $44(28.03)$ \\
Insufficient income & \\
Health insurance & $133(84.71)$ \\
Universal coverage & $24(15.29)$ \\
Government officer/ Social security scheme & \\
Underlining diseases & $66(42.04)$ \\
Hypertension (HT) & $7(4.46)$ \\
Diabetes Mellitus (DM) & $28(17.83)$ \\
HT and DM & $36(22.93)$ \\
HT and Cardiovascular & $4(2.55)$ \\
DM and Cardiovascular & $16(10.19)$ \\
HT, DM, and Cardiovascular & \\
\hline
\end{tabular}

Table 2 The overall score levels of self-esteem, health service system, family relationships, and social support of elderly with NCDs.

\begin{tabular}{ccccccc}
\hline Factors & n & Mean & S.D. & min & max & Interpretation \\
\hline Self-esteem & 157 & 3.86 & 0.46 & 2.39 & 4.83 & Best \\
Health service system accession & 157 & 3.94 & 0.44 & 2.50 & 4.75 & Best \\
Family relationships & 157 & 4.24 & 0.39 & 3.08 & 5.0 & Best \\
Social support & 157 & 3.73 & 0.45 & 2.69 & 5.0 & Best \\
\hline
\end{tabular}

Ninety-nine (63.06 \%) of the elderly were scored as fair QOL, followed by 57 (36.31\%) best QOL and $1(0.64 \%)$ poor QOL (Table 3). The overall average score $( \pm \mathrm{SD})$ of QOL was $91.98( \pm 11.98)$. The mean score $( \pm \mathrm{SD})$ of the physical health domain was $22.48( \pm 3.87)$. The mean score $( \pm \mathrm{SD})$ of the mental health domain was $22.70( \pm 3.21)$. The average score of the social relations' domain was 10.51 $( \pm 1.85)$ and the mean score $( \pm \mathrm{SD})$ of the environment domain was $28.83( \pm 3.99)$ which each domain was listed in the fair level of QOL (Table 4).

Table 3 The quality of life of the elderly in Nakhon Si Thammarat, Thailand.

\begin{tabular}{cc}
\hline Overall quality of life & No. $(\mathbf{\%})(\mathbf{n}=\mathbf{1 5 7})$ \\
\hline Poor $(26-60$ scores $)$ & $1(0.64)$ \\
Fair (61-95 scores) & $99(63.06)$ \\
Best (96-130 scores) & $57(36.31)$ \\
\hline
\end{tabular}


Table 4 The quality of life of the elderly in Nakhon Si Thammarat, Thailand.

\begin{tabular}{ccccccc}
\hline WHOQOL & n & Mean & S.D. & Min & Max & Interpretation \\
WHOQOL-BREF (score 0 - 130) & & & & & & Fair \\
\hline Physical health & 157 & 22.48 & 3.87 & 10.0 & 32.0 & Fair \\
Mental health & 157 & 22.70 & 3.21 & 11.0 & 30.0 & Fair \\
Social relations & 157 & 10.51 & 1.85 & 6.0 & 15.0 & Fair \\
Environment & 157 & 28.83 & 3.99 & 19.0 & 40.0 & Fair \\
\hline Overall quality of life & 157 & 91.98 & 11.98 & 51.0 & 122.0 & \\
\hline
\end{tabular}

According to univariate analysis using simple logistic regression, the elderly in groups of $70-79$ and $\geq 80$ years were not significantly associated with QOL (crude Odds Ratio [cOR] $=1.38,95 \% \mathrm{CI}$ : 0.64 to $2.98, \mathrm{cOR}=1.5,95 \% \mathrm{CI}$ : 0.65 to $3.44, p$-value $>0.05$, respectively). Female was 1.61 times more likely to have poor QOL than male, but this was not significantly associated with QOL (cOR $=1.61,95$ $\% \mathrm{CI}: 0.81$ to $3.21, p$-value $>0.05)$. Although education levels (cOR $=0.74,95 \% \mathrm{CI}: 0.24$ to 2.25$)$, occupation $(\mathrm{cOR}=0.91,95 \% \mathrm{CI}$ : 0.46 to 1.81$)$, and income $(\mathrm{cOR}=0.51,95 \% \mathrm{CI}$ : 0.24 to 1.08$)$ can prevent the decreasing of QOL score among the elderly, these factors were not significantly associated with QOL in this study ( $p$-value $>0.05)$.

The factors associated with QOL among the elderly were income sufficiency, self-esteem, health service system accession, family relationships, and social support. The elderly who had insufficient income was 4.19 times more likely to have poor QOL than the elderly who had sufficient income $(\mathrm{cOR}=$ 4.19; $95 \%$ CI: 1.72 to $10.20, p$-value $<0.001)$. The elderly who had self-esteem at a fair level was 16.61 times more likely to have poor QOL than the elderly who had self-esteem at the excellent level $(\mathrm{cOR}=$ 16.61; $95 \%$ CI: 4.87 to 56.67, $p$-value $<0.001)$. Additionally, the elderly who had the health service system accession at a fair level was 5.68 times more likely to have poor QOL than those who had the health service system accession at the excellent level (cOR 5.68; $95 \% \mathrm{CI}$ : 1.88 to 17.10, $p$-value $<0.001$ ). Furthermore, the increased family relationships score of participants can prevent experiencing poor QOL was $43 \%$ according to the univariate analysis (cOR $0.57 ; 95 \% \mathrm{CI}$ : 0.12 to 0.19 , $p$-value $<0.001$ ). Moreover, the elderly who had social support at a fair level were 2.36 times more likely to face poor QOL than the elderly who had social support at the excellent level (cOR 2.36; $95 \%$ CI: 1.18 to 4.76, $p$-value = 0.01) (Table 5).

According to adjusting confounding factors using multiple logistic regression, the factors associated with QOL in the elderly were income sufficiency, self-esteem, and family relationships. The elderly who had insufficient income was 2.80 times more likely to have poor QOL than the elderly who had sufficient income (adjusted Odds Ratio [aOR] 2.80; $95 \% \mathrm{CI}$ : 1.04 to 7.52, $p$-value $=0.04$ ). The elderly who had self-esteem at a fair level were 9.75 times more likely to have poor QOL than the elderly who had selfesteem at the excellent level (aOR 9.75; $95 \% \mathrm{CI}$ : 2.74 to 34.70, $p$-value $<0.001$ ). Furthermore, the increased family relationships score of participants that can prevent having poor QOL was $88 \%$ according to the multivariate analysis (aOR 0.12; $95 \% \mathrm{CI}$ : 0.031 to $0.430, p$-value $<0.001$ ) (Table 5).

Table 5 Univariable and multivariable analysis of QOL in the elderly on simple logistic regression and multiple logistic regression.

\begin{tabular}{|c|c|c|c|c|}
\hline Variables & No. & $\begin{array}{l}\text { No. poor } \\
\text { QOL (\%) }\end{array}$ & $\operatorname{cOR}(95 \% \mathrm{CI})$ & aOR $(95 \% C I)$ \\
\hline \multicolumn{5}{|l|}{ Age (years) } \\
\hline $60-69$ & 50 & $29(18.47)$ & 1 & \\
\hline $70-79$ & 61 & $40(25.48)$ & $1.38(0.64$ to 2.98$)$ & \\
\hline$\geq 80$ & 46 & $31(19.74)$ & $1.5(0.65$ to 3.44$)$ & \\
\hline \multicolumn{5}{|l|}{ Gender } \\
\hline Male & 50 & $28(17.83)$ & 1 & \\
\hline Female & 107 & $72(45.86)$ & $1.61(0.81 \text { to } 3.21)^{\mathrm{c}}$ & \\
\hline
\end{tabular}




\begin{tabular}{|c|c|c|c|c|}
\hline Variables & No. & $\begin{array}{l}\text { No. poor } \\
\text { QOL }(\%)\end{array}$ & $\operatorname{cOR}(95 \% \mathrm{CI})$ & aOR $(95 \% \mathrm{CI})$ \\
\hline \multicolumn{5}{|l|}{ Living status } \\
\hline Living without partner & 61 & $43(27.39)$ & 1 & \\
\hline Living with partner & 96 & $57(36.30)$ & $0.61(0.31 \text { to } 1.21)^{\mathrm{c}}$ & \\
\hline \multicolumn{5}{|l|}{ Education levels } \\
\hline Primary school or no formal education & 143 & $92(58.59)$ & 1 & \\
\hline Secondary school or higher & 14 & $8(5.10)$ & $0.74(0.24$ to 2.25$)$ & \\
\hline \multicolumn{5}{|l|}{ Occupations } \\
\hline Unemployed & 104 & $67(42.67)$ & 1 & \\
\hline $\begin{array}{l}\text { Employed } \\
\text { (Agriculture 48, merchant 6) }\end{array}$ & 53 & $33(21.02)$ & $0.91(0.46$ to 1.81$)$ & \\
\hline \multicolumn{5}{|l|}{ Income per month $(\$)$} \\
\hline$<160.51 \$$ & 120 & $81(51.59)$ & 1 & \\
\hline$\geq 160.51 \$$ & 37 & $19(12.10)$ & $0.51(0.24 \text { to } 1.08)^{\mathrm{c}}$ & \\
\hline \multicolumn{5}{|l|}{ Income sufficiency } \\
\hline Sufficient income & 113 & $63(40.13)$ & 1 & \\
\hline Insufficient income & 44 & $37(23.56)$ & $4.19(1.72 \text { to } 10.20)^{\mathrm{b}}$ & $2.8(1.04 \text { to } 7.52)^{\mathrm{a}}$ \\
\hline \multicolumn{5}{|l|}{ Health insurance } \\
\hline Universal coverage & 133 & $88(56.05)$ & 1 & \\
\hline Government officer/ Social security scheme & 24 & $12(7.64)$ & $0.51(0.21 \text { to } 1.22)^{\mathrm{c}}$ & \\
\hline \multicolumn{5}{|l|}{ Self-esteem } \\
\hline Excellent & 106 & $52(33.12)$ & 1 & \\
\hline Fair & 51 & $48(30.57)$ & $16.61(4.87 \text { to } 56.67)^{\mathrm{b}}$ & $9.75(2.74 \text { to } 34.70)^{b}$ \\
\hline \multicolumn{5}{|l|}{ Health service system accession } \\
\hline Excellent & 123 & $70(44.58)$ & 1 & \\
\hline Fair & 34 & $30(19.11)$ & $5.68(1.88 \text { to } 17.10)^{\mathrm{b}}$ & \\
\hline \multicolumn{5}{|l|}{ Family relationships } \\
\hline $\operatorname{Mean}(\mathrm{SD})=4.2(0.39), \operatorname{Min}=3.1 \mathrm{Max}=5.0$ & 157 & & $0.57(0.12 \text { to } 0.19)^{\mathrm{b}}$ & $0.12(0.03 \text { to } 0.43)^{\mathrm{b}}$ \\
\hline \multicolumn{5}{|l|}{ Social support } \\
\hline Excellent & 93 & $52(33.12)$ & 1 & \\
\hline Fair & 64 & $48(30.57)$ & $2.36(1.18 \text { to } 4.76)^{\mathrm{a}}$ & \\
\hline
\end{tabular}

${ }^{\mathrm{a}}$ Statistically significant difference $p$-value $<0.05,{ }^{\mathrm{b}}$ Statistically significant $p$-value $<0.001$.

c The variable had a statistically significant difference $p$-value $<0.2$ for backward stepwise regression analysis

\section{Discussion}

In this study, most of the elderly with NCDs had fair QOL levels. This suggests that NCDs impact QOL. These findings were similar to the study in Jordan [19], and Vietnam [20] because Vietnam and Jordan were middle-income countries like Thailand. However, the United States and Switzerland, which found the best QOL in the elderly $[21,22]$ because these countries may have a better economic system and social welfare system than Thailand. According to evaluating the WHOQOL-BREF quality of life questionnaire, we found that each domain, in this study, was listed at the fair level of QOL. However, this differs from the results in Slovakia, which found the best QOL in family relationships and poor QOL in physical health [23].

The present study showed that income sufficiency, self-esteem, and family relationship can be used to predict the QOL. Most of the elderly was unemployed and had a lower income per month. The government's social welfare system was the main source of income for the elderly. So, the elderly who have insufficient income are more likely to have significantly poor QOL compared to those who have sufficient income. This finding was similar to previous studies in Phayao and Khon Kaen, Thailand [2,9]. The elderlies living in a rural community are usually living lower-income and felt that their incomes were not sufficient because the only source of income was from the social welfare system from the government and some may receive an allowance from other members of the family [2,9]. Additionally, the insufficient 
income of the elderly can result to reduce health services accession [24]. Therefore, this point is an important gap between actual needs and social welfare.

This study showed that the elderly had excellent self-esteem 52 (33.12\%). Furthermore, our results supported that the elderly who had a fair level of self-esteem was shown to have a high impact on the poor QOL. Likewise, previous studies presented that the elderly who had high self-esteem were motivated to take care of themselves which can lead to a better QOL [6,24]. Similarly, Tavares et al. (2016) reported that the elderly with low self-esteem were related to low QOL [24]. Thus, self-esteem can prove to be interrelated with QOL in an individual's perceptions of the elderly [24,25]. Moreover, the elderly in this study had a mean (SD) family relationship of 4.2 (0.39). Our results supported that a high score in family relationships was also associated with increased QOL scores in the elderly with NCDs, which is similar to the previous studies [26-29]. The results demonstrated that the relationship with family, friends, neighbors, and other residents were associated with increased QOL in the elderly [26-29]. Therefore, the family relationship is 1 factor to encourage the elderly to contribute to activities provided by the community and health care in their area [24].

In this study, a female was more likely to have poor QOL than a male. These findings likewise to the previous study [19,23,30,31]. Female is likely to be more concerned about their health conditions and their impact on the family environment than men, thus females were poor QOL than males [19]. In this study, living with a partner of seniors can help them have high QOL but this factor was not significantly associated with QOL. In contrast, Soósová [23]; Dahlberg and McKee [30] suggested that living without a partner associated with the mood of the elderly such as loneliness and depression which causes low QOL. Therefore, children in the family and strong social networks are important roles both in helping to cope with living without a partner and in preventing isolation and social and emotional loneliness. Moreover, secondary school or higher educational level, the elderly who had working and had income $\geq$ $160.51 \$$ per month, and health insurance via government or social security scheme can help the elderly have high QOL but these factors were not significantly associated with QOL. These findings contrasted with the previous study [28,32,33]. Marventano et al. [28] reported that education levels were significantly associated with QOL in previous studies. The elderly who had higher education have a high health literacy, a stronger awareness of self-care, health care, and they can learn and understand more about the disease by all kinds of methods and actively cooperate with therapeutic nursing [32]. Furthermore, the elderly who had high education had more skilled in the psychological state of selfregulation [32].

\section{Conclusions}

Currently, Thailand has become an aging society. This study suggested that self-esteem, social support, and income sufficiency were associated with QOL in the elderly with NCDs. Therefore, a program for health and QOL in the elderly should be considered. A program should include promoting self-esteem, getting social support, and making an opportunity to increase fixed income in the elderly with NCDs for the good plan for health and best QOL in the elderly.

\section{Acknowledgments}

We gratefully acknowledge the Directors and all staff of Bangsala sub-district health promoting hospital and for their support throughout the course of this study.

\section{References}

[1] World Health Organization. US National Institute of Aging. Available at: https://www.who.int/ageing/publications/global_health/en, accessed January 2020.

[2] D Hongthong, R Somrongthong and P Ward. Factors influencing the quality of life (Qol) Among thai older people in a rural area of Thailand. Iran J. Publ. Health 2015; 44, 479-85.

[3] H Kim and K Kim. Health-related quality-of-life and diabetes self-care activity in elderly patients with diabetes in Korea. J. Community Health 2017; 42, 998-1007.

[4] A Boutayeb and S Boutayeb. The burden of non-communicable diseases in developing countries. Int. J. Equity Health 2005; 4, 2.

[5] World Health Organization. Noncommunicable diseases country profiles. World Health Organization, Geneva, Switzerland, 2018. 
[6] S Nanthamongkolchai, C Tuntichaivanit, C Munsawaengsub and P Charupoonphol. Factors influencing life happiness among elderly female in Rayong Province, Thailand. J Med. Assoc. Thai. 2009; 92, S8-S12.

[7] A Dans, N Ng, C Varghese, ES Tai, R Firestone and R Bonita. The rise of chronic noncommunicable diseases in southeast Asia: Time for action. Lancet 2011; 377, 680-9.

[8] National Statistical Office, Ministry of Information and Communication and Technology. Older persons in Thailand. Available at: http://web.nso.go.th/en/survey/age/older07.htm, accessed December 2019.

[9] R Somrongthon, S Wongchalee, K Yodmai, P Kuhirunyaratn and SMS Sihapark. Quality of life and health status among Thai elderly after economic crisi, Khon Kanen province, Thailand. Eur. J. Sci. Res. 2013; 112, 314-24.

[10] World Health Organization, Regional Office for South-East Asia. Noncommunicable diseases in the South-East Asia Region, 2011: Situation and response. World Health Organization, New Delhi, India, 2012.

[11] Bureau of Non-Communicable Disease. Number and prevalence rate of high blood pressure per 100,000 population (including all diagnoses) 2016 - 2018. Available at: http://www.thaincd.com/2016/mission/documents-detail.php?id=13684\&tid=32\&gid=1-020, accessed December 2019.

[12] Nakhon Si Thammarat Public Health Office. Population pyramid. (in Thai). Available at: https://nrt.hdc.moph.go.th/hdc/reports/report.php?source=populationpyramid.php\&cat id=ac4eed1b ddb23d6130746d62d2538fd0\&id=db4e8d42e1234a75bd03d430c31feb2f, accessed December 2019.

[13] World Health Organization. Classification of diabetes mellitus 2019. Available at: https://www.who.int/publications-detail/classification-of-diabetes-mellitus, accessed December 2019.

[14] World Health Organization, Regional Office for the Eastern Mediterranean 2005. Clinical guidelines for the management of hypertension. Available at: https://apps.who.int/iris/handle/10665/119738, accessed December 2019.

[15] WD Wayne. Biostatistics: A foundation of analysis in the health sciences. $6^{\text {th }}$ ed. John Wiley\&Sons, New York, 1995, p. 191-2.

[16] The WHOQOL Group. Development of the World Health Organization WHOQOL-BREF quality of life assessment. Psychol. Med. 1998; 28, 551-8.

[17] RF Baumeister. The self in social psychology. Psychology Press, Philadelphia, 1999, p. 225-37.

[18] R Penchansky and JW Thomas. The concept of access: Definition and relationship to consumer satisfaction. Med. Care 1981; 19, 127-40.

[19] AA Alrub, D Hyassat, YS Khader, R Bani-Mustafa, N Younes and K Ajlouni. Factors associated with health-related quality of life among Jordanian patients with diabetic foot ulcer. J. Diabetes Res. 2019; 2019, 4706720.

[20] HV Nguyen, TT Tran, CT Nguyen, TH Tran, BX Tran, CA Latkin, CSH Ho and RCM Ho. Impact of comorbid chronic conditions to quality of life among elderly patients with diabetes mellitus in Vietnam. Int. J. Environ. Res. Publ. Health 2019; 16, 531.

[21] M Baernholdt, I Hinton, G Yan, K Rose and M Mattos. Factors associated with quality of life in older adults in the United States. Qual. Life Res. 2012; 21, 527-34.

[22] MA Bornet, E Rubli Truchard, E Rochat, J Pasquier and S Monod. Factors associated with quality of life in elderly hospitalised patients undergoing post-acute rehabilitation: A cross-sectional analytical study in Switzerland. BMJ Open 2017; 7, e018600.

[23] MS Soósová. Determinants of quality of life in elderly. Cent. Eur. J. Nurs. Midw. 2016; 7, 484-93.

[24] DM Tavares, TG Matias, PC Ferreira, MS Pegorari, JS Nascimento and MM Paiva. Quality of life and self-esteem among the elderly in the community. Ciencia Saude Coletiva 2016; 21, 3557-64.

[25] The WHOQOL Group. The World Health Organization quality of life assessment (WHOQOL): Position paper from the World Health Organization. Soc. Sci. Med. 1995; 41, 1403-9.

[26] LM Byrne-Davis, PD Bennett and GK Wilcock. How are quality of life ratings made? Toward a model of quality of life in people with dementia. Qual. Life Res. 2006; 15, 855-65.

[27] L Clare, RT Woods, SM Nelis, A Martyr, IS Markova, I Roth, CJ Whitaker and RG Morris. Trajectories of quality of life in early-stage dementia: individual variations and predictors of change. Int. J. Geriatr. Psychiatr. 2014; 29, 616-23.

[28] S Marventano, ME Prieto-Flores, B Sanz-Barbero, S Martin-Garcia, G Fernandez-Mayoralas, F Rojo-Perez, P Martinez-Martin, MJ Forjaz and Spanish Research Group on Quality of Life and 
Ageing. Quality of life in older people with dementia: A multilevel study of individual attributes and residential care center characteristics. Geriatr. Gerontol. Int. 2015; 15, 104-10.

[29] W Moyle, L Venturto, S Griffiths, P Grimbeek, M McAllister, D Oxlade and J Murfield. Factors influencing quality of life for people with dementia: a qualitative perspective. Aging Ment. Health $2011 ; \mathbf{1 5}, 970-7$.

[30] L Dahlberg and KJ McKee. Correlates of social and emotional loneliness in older people: Evidence from an English community study. Aging Ment. Health 2014; 18, 504-14.

[31] ML Barca, K Engedal, J Laks and G Selbaek. Quality of life among elderly patients with dementia in institutions. Dement Geriatr. Cogn. Disord. 2011; 31, 435-42.

[32] XJ Li, C Suishu, S Hattori, HD Liang, H Gao, CQ Feng and FL Lou. The comparison of dementia patient's quality of life and influencing factors in two cities. J. Clin. Nurs. 2013; 22, 2132-40.

[33] M Mjørud, J Røsvik, AMM Rokstad, M Kirkevold and K Engedal. Variables associated with change in quality of life among persons with dementia in nursing homes: A 10 months follow-up study. PloS One 2014; 9, e115248. 